\title{
OPEN Molecular and functional characterization of detrusor PDGFR $\alpha$ positive cells in spinal cord injury-induced detrusor overactivity
}

Ken Lee ${ }^{1,6}$, Sang O Park ${ }^{2,6}$, Pil-Cho Choi, ${ }^{3,6}$, Seung-Bum Ryoo ${ }^{4,6}$, Haeyeong Lee ${ }^{1,6}$ Lauren E. Peri ${ }^{1}$, Tong Zhou ${ }^{1}$, Robert D. Corrigan ${ }^{1}$, Andrew C. Yanez ${ }^{1}$, Suk B. Moon ${ }^{5}$, Brian A. Perrino ${ }^{1}$, Kenton M. Sanders ${ }^{1}$ \& Sang Don Koh ${ }^{1 凶}$

Volume accommodation occurs via a novel mechanism involving interstitial cells in detrusor muscles. The interstitial cells in the bladder are PDGFR $\alpha^{+}$, and they restrain the excitability of smooth muscle at low levels and prevents the development of transient contractions (TCs). A common clinical manifestation of spinal cord injury ( $\mathrm{SCl}$ )-induced bladder dysfunction is detrusor overactivity (DO). Although a myogenic origin of $\mathrm{DO}$ after $\mathrm{SCl}$ has been suggested, a mechanism for development of SCIinduced DO has not been determined. In this study we hypothesized that $\mathrm{SCl}$-induced $\mathrm{DO}$ is related to loss of function in the regulatory mechanism provided by PDGFR $\alpha^{+}$cells. Our results showed that transcriptional expression of $P d g f r a$ and $K c n n 3$ was decreased after $\mathrm{SCl}$. Proteins encoded by these genes also decreased after $\mathrm{SCl}$, and a reduction in PDGFR $\alpha^{+}$cell density was also documented. Loss of PDGFR $\alpha^{+}$cells was due to apoptosis. TCs in ex vivo bladders during filling increased dramatically after $\mathrm{SCl}$, and this was related to the loss of regulation provided by SK channels, as we observed decreased sensitivity to apamin. These findings show that damage to the mechanism restraining muscle contraction during bladder filling that is provided by PDGFR $\alpha^{+}$cells is causative in the development of DO after SCl.

As the bladder fills with urine the volume increases, but during much of the filling period, intravesical pressure remains low ${ }^{1}$. This accommodation occurs even though stretch-dependent ion channels in smooth muscle cells (SMCs) would tend to make contraction of the detrusor a probable response to stretch ${ }^{2,3}$. However, during bladder filling, non-voiding contractions (NVCs) which are transient increases in intraluminal pressure, occur in cystometric records from all species including human. NVCs appear to correspond to localized contractions that are also observed in ex vivo bladder preparations and have been termed 'spontaneous phasic contractions', 'micro-

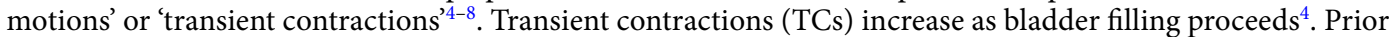
experiments have shown that TCs are initiated by stretch-dependent non-selective cation channels expressed by detrusor $\mathrm{SMC}^{2,3}$. Inward currents generated by these channels depolarize SMCs and activate L-type $\mathrm{Ca}^{2+}$ channels, causing generation of $\mathrm{Ca}^{2+}$ action potentials, $\mathrm{Ca}^{2+}$ entry into SMCs and contraction. Action potentials propagate to other SMCs within the same muscle bundle, but do not spread to adjacent muscle bundles.

Several studies suggest that TCs initiate afferent nerve activity and provide a major source of the sensory information conveyed to the central nervous system during bladder filling ${ }^{9-12}$. A recent study has clearly demonstrated the link between TCs and sensory output from bladder ${ }^{4}$. Increased TCs may correspond to the sensory and

\footnotetext{
${ }^{1}$ Department of Physiology and Cell Biology, University of Nevada School of Medicine, Reno, NV 89557, USA. ${ }^{2}$ Department of Emergency Medicine, Konkuk University School of Medicine, Seoul, South Korea. ${ }^{3}$ Department of Emergency Medicine, Kangbuk Samsung Hospital, Sungkyunkwan University, Seoul, South Korea. ${ }^{4}$ Department of Surgery, Seoul National University Hospital, College of Medicine, Seoul National University, Seoul, South Korea. ${ }^{5}$ Department of Surgery, School of Medicine, Kangwon National University, Chuncheon, South Korea. ${ }^{6}$ These authors contributed equally: Ken Lee, Sang O Park, Pil-Cho Choi, Seung-Bum Ryoo and Haeyeong Lee. ${ }^{\boxplus}$ email: skoh@med.unr.edu
} 

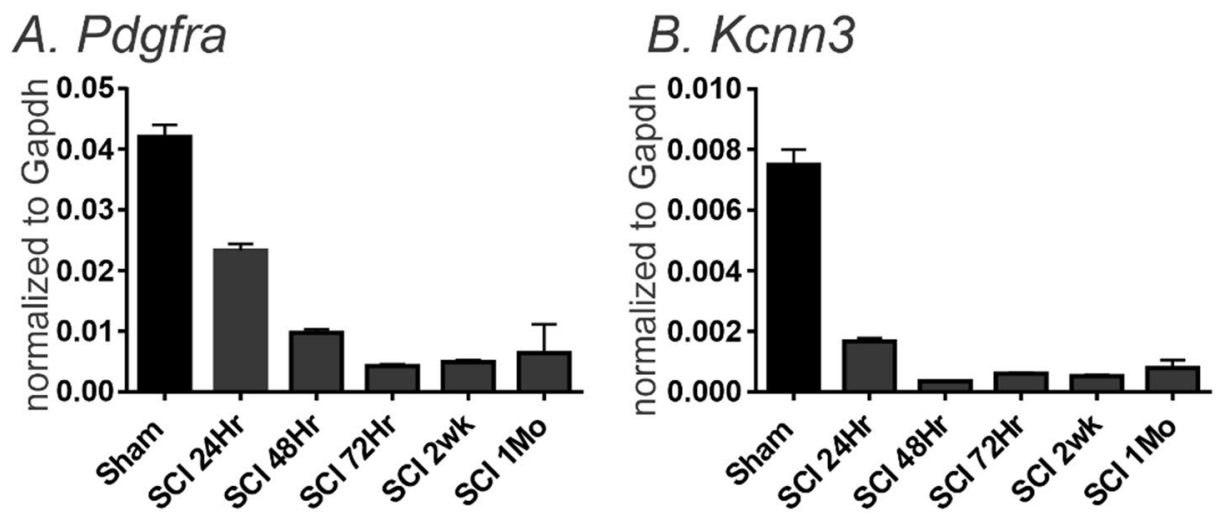

\section{C. sorted PDGFR $\alpha^{+}$cell}

\section{D. sorted SMC}
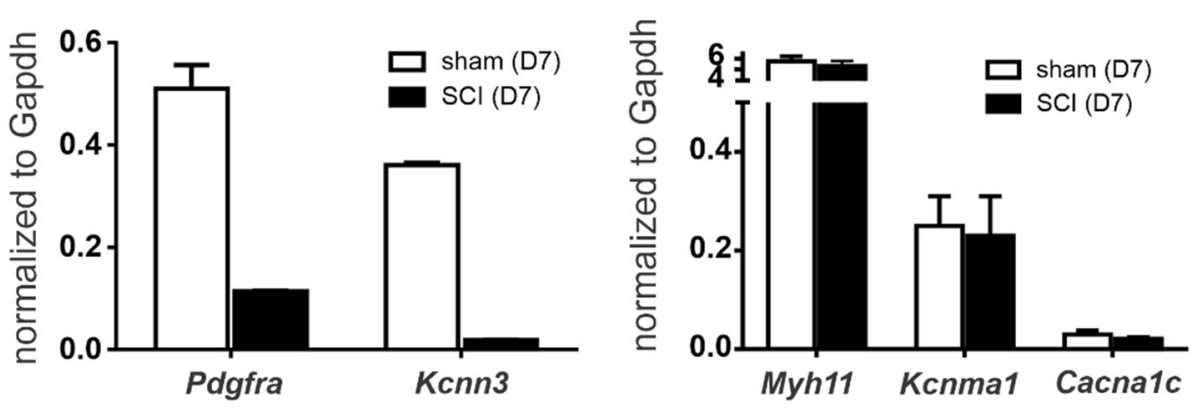

Figure 1. Quantitative analysis of transcripts in control and after SCI. (A,B) Pdgfra and Kcnn3 transcripts are decreased up to $1 \mathrm{mo}$ after SCI in detrusor muscles. (C) Transcripts of Pdgfra and Kcnn3 from sorted PDGFRa ${ }^{+}$ cells in SCI (D7) decreased compared to control (D7). (D) Transcripts including Myh11, Kcnma1 and Cacna1C from sorted SMCs showed no significant change in SCI (D3). Error bars denote standard deviation from $\mathrm{n}=4$.

mechanical behaviors associated with detrussor overactivity (DO). Normal bladders have the means to restrain development of TCs, but experiments have not been sufficiently rigorous to reveal the mechanisms responsible for restraining bladder excitability and the development of TCs during filling.

We discovered a novel mechanism involving interstitial cells in detrusor muscles. Interstitial cells of the bladder were previously identified as c-Kit ${ }^{+}$cells and thought to provide excitatory input to the detrusor ${ }^{13,14}$, but more recent immunohistochemical evaluation showed few c-Kit ${ }^{+}$cells, other than mast cells, are found in bladders of several species ${ }^{15}$. In fact the major population of interstitial cells in the bladder is platelet-derived growth factor receptor alpha positive cells (PDGFRa ${ }^{+}$cells). These cells provide inhibitory regulation of detrusor muscles due to activation of small conductance $\mathrm{Ca}^{2+}$-activated $\mathrm{K}^{+}$channels (SK channels) ${ }^{16-20}$. Inhibitory regulation is enhanced by purines and by stretch, making it an ideal mechanism for control detrusor excitability and restraining the development of TCs during bladder filling. Rigorous confirmation of the hypothesis that inhibitory regulation during bladder filling is provided by $\mathrm{PDGFRa}^{+}$cells would be to demonstrate pathological conditions where DO develops in association with loss or remodeling of PDGFRa ${ }^{+}$cells. Therefore, we evaluated the status of PDGFR $\alpha^{+}$cells in spinal cord injury (SCI) animal models that develop DO.

Clinical manifestations of SCI-induced bladder dysfunction involve a combination of storage and voiding problems. A myogenic origin of DO after SCI has also been suggested due to abnormal muscle reactivity ("the myogenic hypothesis") ${ }^{21}$ without studying precise mechanisms for DO after SCI. In this study we investigated the mechanisms of DO using murine SCI model.

\section{Results}

1. Changes in transcriptional expression of SCI-induced detrusor muscles

We harvested detrusor muscles from control (sham) mice and 1, 2, 3, 7, 14 and 30 days (D1-D30) after SCI. Pdgfra and Kcnn3 expression were decreased in detrusor muscles $24 \mathrm{~h}$ after SCI. Reduced Pdgfr $\alpha$ and Kcnn3 expression persisted for at least 1 month after SCI $(\mathrm{n}=4$, Fig. 1A,B). Pdgfra and Kcnn 3 expression also decreased in sorted PDGFRa ${ }^{+}$cells SCI D7, as compared with sorted PDGFRa $\alpha^{+}$cells from control mice $(n=4$, Fig. 1C). We also isolated and sorted smooth muscle cells (SMCs) from smMHC/eGFP mice. Expression of Myh11 (SM myosin heavy chain), Kcnma1 (BK $\alpha_{\text {slo }}$ ) and Cacna1C (Cav1.2) were unchanged in SMCs after SCI $(n=4$, Fig. 1D).

2. Changes in protein expression in SCI-induced detrusor muscles 


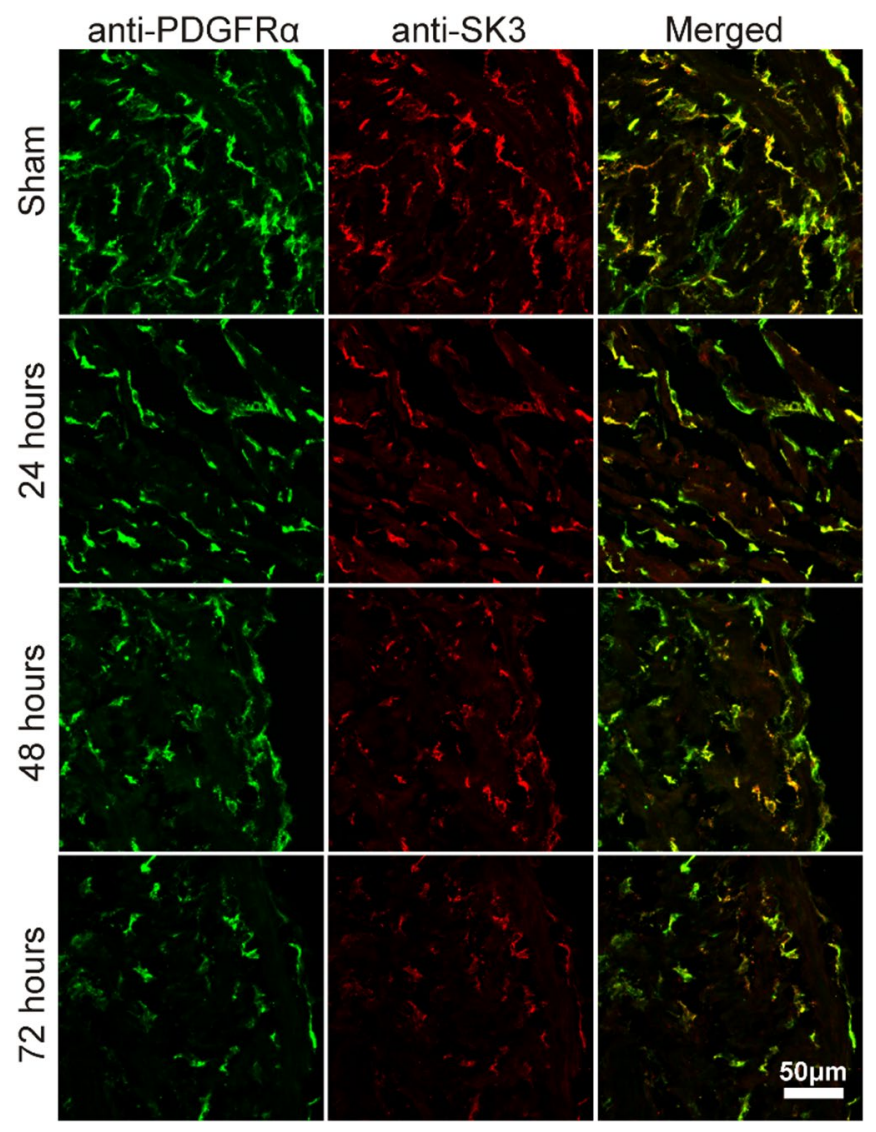

Figure 2. PDGFRa immunoreactivity of detrusor muscle layer in control and SCI. Immunoreactivity of PDGFRa (green) and SK3 (red) in control (sham). SCI (24 h, $48 \mathrm{~h}$ and $72 \mathrm{~h}$ ).

Three approaches were used to characterize changes in protein expression. Firstly, immunohistochemistry was used to examine the expression and distribution of PDGFR $\alpha$ and SK3 immunoreacitvity in SCI. PDGFR $\alpha$ and SK3-like immunoreactivity decreased in detrusor muscles after SCI in a time dependent manner (Fig. 2). We also used PDFGRa/eGFP mice and counted the number of nuclei containing eGFP in control and after SCI. Nuclei with eGFP decreased after SCI (D3 and D7) compared to control. Since bladder distension can occur after SCI, nuclei with eGFP per unit area could be misleading. Therefore, we normalized the number of eGFP positive nuclei against the total area of the bladders (e.g. $63 \mathrm{~mm}^{2}$ in control vs $111 \mathrm{~mm}^{2}$ in SCI, $\mathrm{n}=3$, respectively). PDGFRa ${ }^{+}$cells also decreased to 53\% (D3) and 35\% (D7) after SCI in PDGFRa/eGFP mice, (Fig. 3A-C). We confirmed these findings by Western analysis and verified reduction in PDGFRa protein in detrusor muscles of SCI mice $(n=4$, Fig. 3D,E). These findings were consistent with the transcriptional changes observed after SCI (see Fig. 1), and suggest overall reduction in PDGFRa ${ }^{+}$cells and reduced expression of SK3 that would negatively impact the regulation of excitability provided by PDGFRa ${ }^{+}$cells in the bladder.

3. Apoptosis of PDGFRa ${ }^{+}$cells in SCI

We examined changes in the expression of apoptosis pathways to better understand the fate of PDGFRa ${ }^{+}$ cells after SCI. RNA-seq of whole muscle samples showed geneset scores computed for the apoptosis-related KEGG and GOBP terms, respectively, using the FAIME algorithm ${ }^{22}$. The apoptosis-related geneset score was significantly increased (t-test: $P<0.05)$ in detrusor muscles after SCI (Fig. 4A). Apoptosis-related genes, including Apaf1, Capns1, and Casp3, were significantly upregulated $(\mathrm{FC}>1.5$ and $F D R<0.05)$ in detrusor muscles SCI D3 (Fig. 4B). Time dependent increases in expression of Apaf1 (Fig. 4C) and Caspase3 (Fig, 4D) in detrusor muscles after SCI (as compared to control; $n=4$ for each period) were confirmed by qPCR.

4. Ex vivo preparation to confirm the role of PDGFRa ${ }^{+}$cells in SCI

Ex vivo bladder preparations were used to characterize the relationship between intravesical volumes and pressures in bladders after SCI. Ex vivo preparation can exclude extrinsic neural reflexes during filling. SK channels are highly expressed in detrusor PDGFRa + cells, and antagonists of these channels increase TCs during filling17. We examined the effects of the SK channel antagonist, Apamin (300 nM) on bladders from control and after SCI (up to $1 \mathrm{Mo}$ ).

In control preparations, infusion of Krebs-Ringer bicarbonate solution $(20 \mu \mathrm{l} / \mathrm{min})$ generated repeatable responses consisting of small amplitude, low frequency of TCs (Fig. 5A). Apamin ( $300 \mathrm{nM}$ added to the bathing 

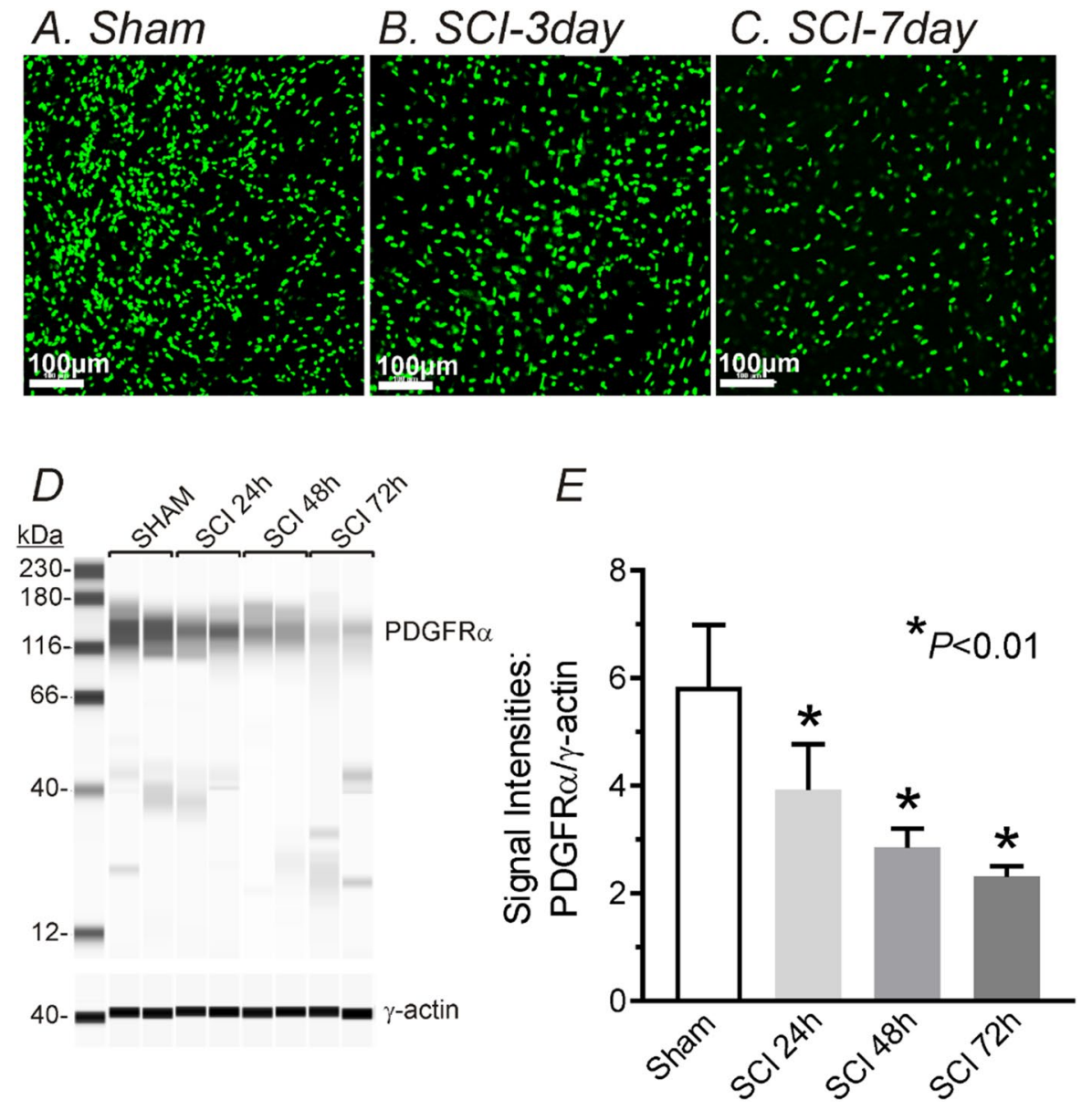

Figure 3. Density of PDFGRa/eGFP cells and microcapillary electrophoresis and immunodetection of PDGFRa by WES in control and SCI detrusor muscles. (A-C) Far fewer eGFP ${ }^{+}$nuclei (reporter for $\mathrm{PDGFRa}^{+}$ cells) were found in detrusor muscles after SCI. (D) Representative Wes full length gel image of PDGFRa expression in murine detrusor muscles following SCI. 100,000 $\times g$ pellet, $1 \mu \mathrm{g} / \mathrm{lane}, \gamma$-action was used for normalization. (E) Normalized signal intensities of PDGFRa by g-actin following SCI periods.

solution) increased the amplitude $\left(6.9 \pm 1.2 \mathrm{cmH}_{2} \mathrm{O}, \mathrm{P}<0.01\right)$ and frequency $(65 \pm 12$ events, $\mathrm{P}<0.01, \mathrm{n}=11)$ of TCs during bladder filling, as compared to control $\left(2.1 \pm 0.5 \mathrm{cmH}_{2} \mathrm{O}\right.$ in amplitude and $22 \pm 9.1$ events in frequency; Fig. 5A, Table 1). At D1, D3, D7, D14 and D30 after SCI, the amplitude and frequency of TCs during filling were increased (Fig. 5B-F, Table 1). Enhanced TCs during filling persisted for at least 30 days after SCI, and apamin failed to induce significant changes of amplitude (from D7) and frequency (from D1) of TCs after SCI (Fig. 5B-F, Table 1) indicating that development of DO after SCI progressed for up to 1 month after SCI. Bladder capacity and filling time to reach $30 \mathrm{cmH}_{2} \mathrm{O}$ were also increased in all of SCI groups compared to control (Table 2). The enlarged bladder capacity due to lack of voluntary voiding and prolonged infusion time was prominent at 30 days after SCI.

\section{Discussion}

In this study we investigated responses of the murine bladder and the status of PDGFRa ${ }^{+}$cells after SCI. PDGFR $\alpha^{+}$cells and the regulatory functions provided by these cells in regulating bladder contractions during filling were greatly decreased after SCI. TCs increased dramatically during bladder filling, and accompanying this change in function, Pdgfra and Kcnn3 expression decreased. PDGFRa and SK3 proteins in detrusor muscles also decreased. Loss of PDGFRa ${ }^{+}$cells due to apoptosis was also observed in detrusor muscles. The increase in TCs was associated with decreased sensitivity to apamin and SKA-31 during bladder filling, which is consistent with the reduced expression of SK3 and loss of PDGFR $\alpha^{+}$cells that express SK3 channels. These findings demonstrate a novel mechanism for development of DO after SCI that is linked to loss of the inhibitory regulation provided by PDGFRa ${ }^{+}$cells during bladder filling.

$\mathrm{PDGFRa}^{+}$cells regulate detrusor excitability during bladder filling ${ }^{23}$. SK channel antagonists potentiate the amplitude of spontaneous contractions in murine ${ }^{24}$, guinea pig $^{25}$ and human ${ }^{26}$ detrusor muscles. The effects of apamin are likely due to blocking SK channels in PDGFRa ${ }^{+}$cells which have a high expression of SK3 channels, because the current density from SK channels is minimal in SMCs and not resolvable in murine SMCs at physiological potentials ${ }^{27}$. Thus, PDGFR $\alpha^{+}$cells express a powerful mechanism to suppress excitability and 
A

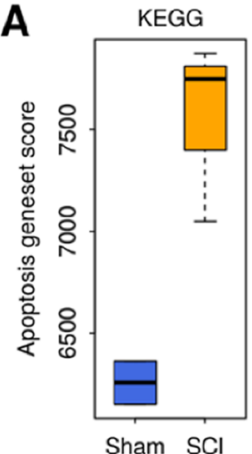

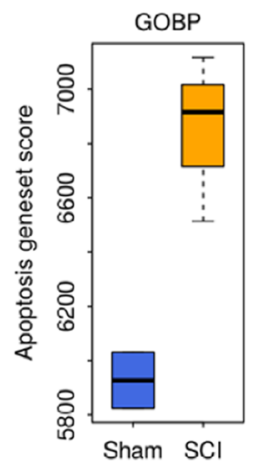
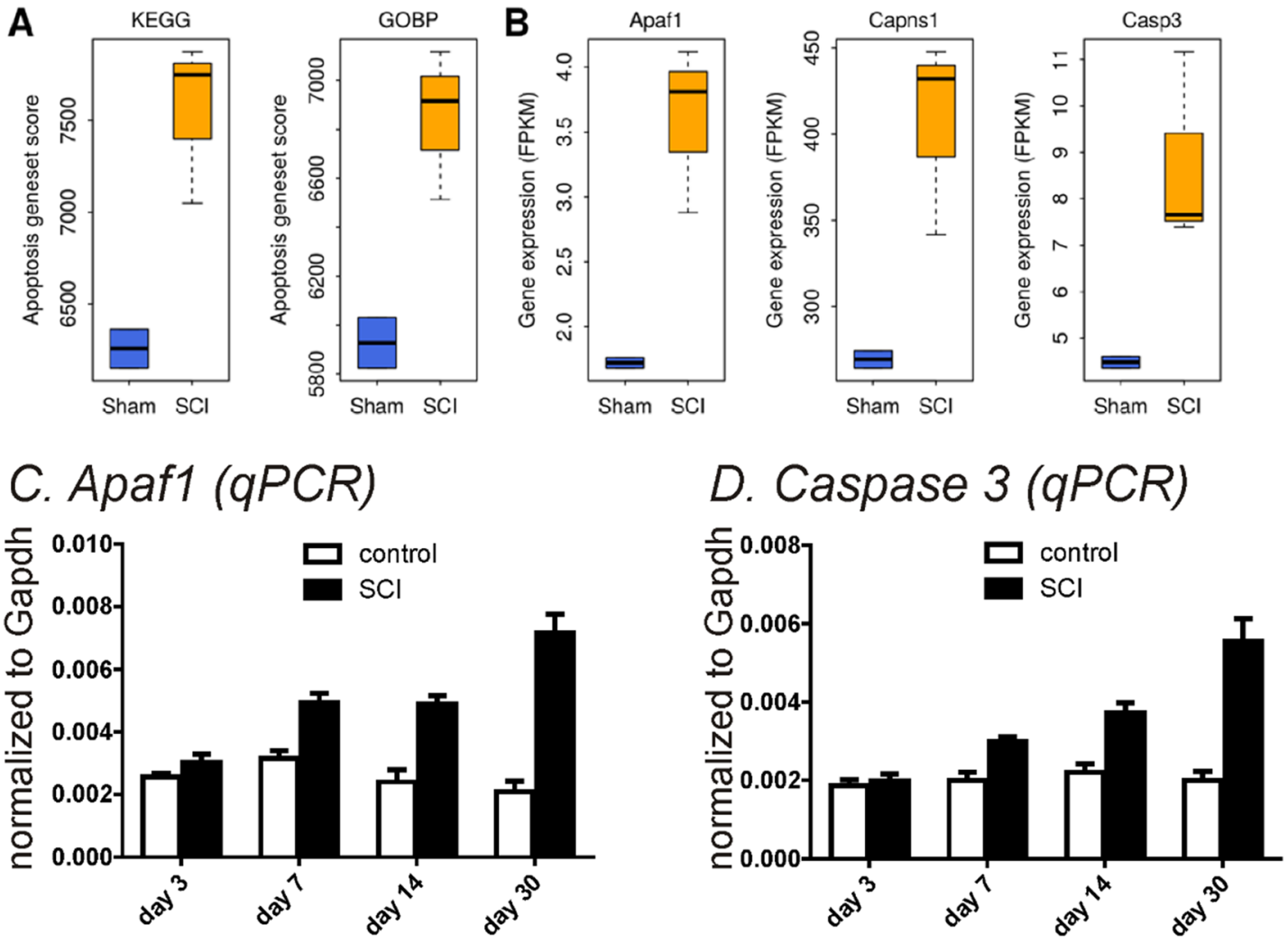

Figure 4. SCI -induced alteration in apoptosis-related genes by RNA-seq (A,B) and qPCR (C,D). (A) Apoptosis geneset scores upregulated in SCI for both the KEGG and GOBP definitions. (B) Expression of three apoptosisrelated genes were upregulated in SCI. (C,D). qPCR from sorted PDGFRa ${ }^{+}$cells in SCI up to 30 days showed an increased in apoptosis-related transcripts (Apaf1 in (C) and Caspase3 in (D)).

allow the bladder to fill with minimal activation of TCs and sensory discharge ${ }^{23}$. Downregulation of Pdgfra and Kcnn3 genes occurred in detrusor PDGFRa ${ }^{+}$cells and can explain the development of DO after SCI. Indeed, transcriptional analysis revealed downregulation of Pdgfra and Kcnn3 in early stage of SCI bladder. In contrast the phenotype of SMCs seemed more stable after SCI, since no changes were observed in key genes, such as Myh11, Kcma1 and Cacnalc.

IHC showed that the distribution of PDGFRa ${ }^{+}$cells decreases in detrusor muscles after SCI. The immunohistochemistry findings were confirmed using a reporter strain of mice with expression of eGFP in nuclei of $\mathrm{PDGFRa}^{+}$cells, as a relatively low density of $\mathrm{eGFP}^{+}$cells was found in bladders of PDGFRa/eGFP mice after SCI. However, IHC is not reliable method to quantify loss of protein, so protein expression in extracts of detrusor muscles was measured by Western analyses. Western blots showed the downregulation of PDGFRa expression and SK3 expression which was mirrored by transcriptional expression.

Loss of PDGFRa ${ }^{+}$cells caused by SCI were due to apoptotic changes in detrusor PDGFRa ${ }^{+}$cells although the mechanism inducing apoptosis in detrusor PDGFRa ${ }^{+}$cells by SCI has not been elucidated. Apaf1 as well as caspase 3 increased after SCI in comparison to control indicating that cell death occurred as a result of SCI. The mechanism causing damage to the regulatory function provided by PDGFRa ${ }^{+}$cells after SCI is an important topic for future research.

Ex vivo preparations were used in the present study to isolate bladders and exclude connections from central and spinal reflexes. Release of mediators from the urothelium may also influence detrusor excitability, but substances and receptors involved in such a mechanism have not been identified. Ex vivo bladder developed increased TCs after SCI as compared to control bladders (see Table 1), and enhanced TCs persisted for at least 30 days after SCI. Effects of apamin on responses to bladder filling remained for up to $72 \mathrm{~h}$ after SCI, but the sensitivity to apamin decreased after SCI due to partial loss of PDGFRa ${ }^{+}$cells and downregulation of SK 3 channels. These findings, observed in ex vivo bladders, describe a novel myogenic mechanism that is sufficient for development of DO after SCI.

SCI patients have less opportunity to see a urologist due to other complications that often require more urgent attention than bladder dysfunction. This prevents patients from early and appropriate examination and treatment of lower urinary tract dysfunction in the early phase of SCI. Although there are many reports of DO after recovery from spinal shock ${ }^{28-33}$, only a few reports confirm development of DO in the acute phase of SCI (i.e. 3-40 days after SCI ${ }^{34,35}$. During the period of spinal shock (1-2wks after SCI in rodents), the initial areflexia bladder and urinary retention occur due to a lack of voiding contractions ${ }^{36-38}$. Unfortunately, the initial urodynamic changes during the spinal shock phase have not been investigated due to possible complications ${ }^{39}$. Thus, convincing in vivo cystometry data characterizing bladder function during the spinal shock phase after 
A. Sham

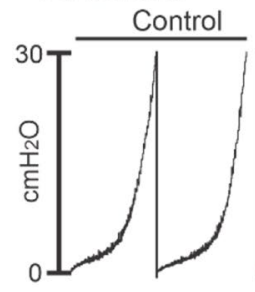

Aa. control

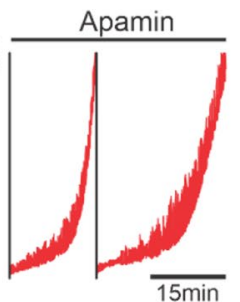

Ab. apamin

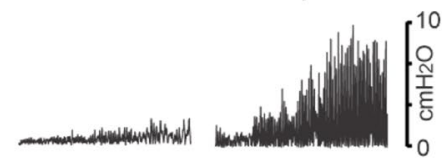

D. D7 after SCI

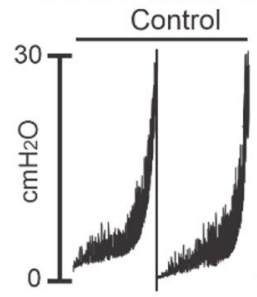

Da. control

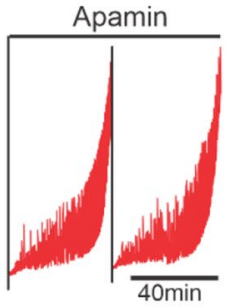

Db. apamin
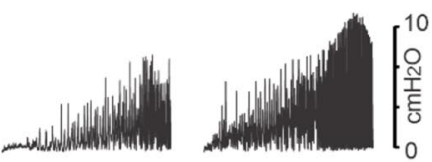

B. D1 after SCI

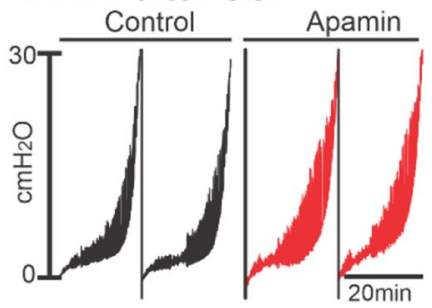

Ba. control

Bb. apamin
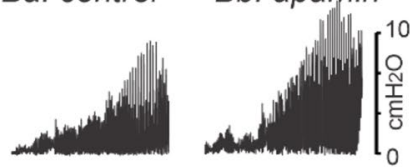

E. D14 after SCI

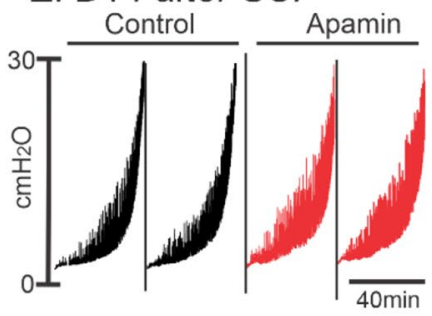

Ea. control

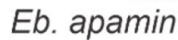

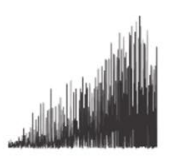

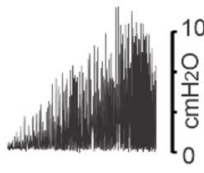

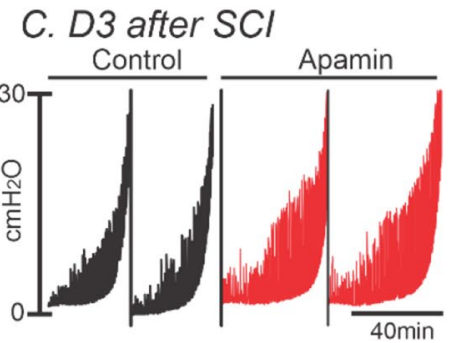

Ca. control

Cb. apamin

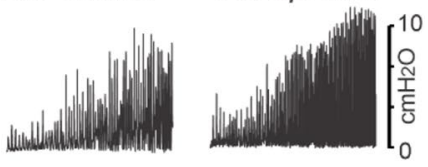

F. D30 after SCI

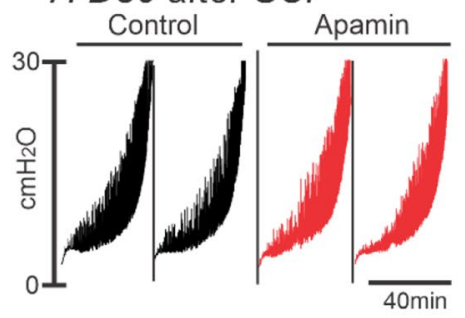

Fa. control

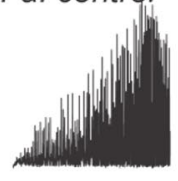

Figure 5. The effects of apamin on transient contractions (TCs) of sham, D1, D3, D7, D14 and D30 after SCI using ex vivo preparation. (A-F) Ex vivo pressure-response curve for control and apamin application. (Aa,b$\mathbf{F a}, \mathbf{b})$ Expanded time scales with adjustment of baseline under control (a) and apamin (b) from above panels.

\begin{tabular}{|c|l|l|l|l|}
\hline & \multicolumn{3}{|l|}{$\begin{array}{l}\text { Frequency (events per } \\
\text { min) }\end{array}$} & \multicolumn{2}{l|}{$\begin{array}{l}\text { Peak amplitude } \\
\left(\mathrm{cmH}_{2} \mathbf{O}\right)\end{array}$} \\
\cline { 2 - 5 } & Control & Apamin & Control & Apamin \\
\hline Control $(\mathrm{n}=11)$ & $22 \pm 9.1$ & $65 \pm 12.0^{*}$ & $2.1 \pm 0.5$ & $6.9 \pm 1.2^{*}$ \\
\hline $\mathrm{D} 1(\mathrm{n}=10)$ & $52 \pm 9.7^{\star}$ & $71 \pm 13.4$ & $4.8 \pm 1.2^{\star}$ & $7.2 \pm 1.5^{*}$ \\
\hline $\mathrm{D} 3(\mathrm{n}=12)$ & $56 \pm 11.1^{*}$ & $69 \pm 11.7$ & $5.1 \pm 0.6^{*}$ & $7.8 \pm 1.1^{*}$ \\
\hline $\mathrm{D} 7(\mathrm{n}=9)$ & $55 \pm 10.8^{*}$ & $64 \pm 9.2$ & $5.9 \pm 1.2^{*}$ & $7.2 \pm 1.4$ \\
\hline $\mathrm{D} 14(\mathrm{n}=6)$ & $67 \pm 10.4^{*}$ & $69 \pm 11.6$ & $7.0 \pm 1.3^{\star}$ & $8.3 \pm 2.3$ \\
\hline $\mathrm{D} 30(\mathrm{n}=6)$ & $96 \pm 6.7^{*}$ & $98 \pm 4.1$ & $6.6 \pm 0.7^{*}$ & $6.9 \pm 0.5$ \\
\hline & & & & \\
\hline
\end{tabular}

Table 1. Summarized data of frequency and amplitude before and after apamin. ${ }^{\star} \mathrm{P}<0.05$ denotes comparison between control and each period after SCI. ${ }^{\#} \mathrm{P}<0.05$ denotes comparison of effects of apamin at each period.

\begin{tabular}{|l|l|l|}
\hline & Infusion volume $(\boldsymbol{\mu l})$ & Infusion time $(\min )$ \\
\hline Control $(\mathrm{n}=11)$ & $298 \pm 53$ & $11.9 \pm 2.0$ \\
\hline D1 $(\mathrm{n}=10)$ & $432 \pm 95^{\star}$ & $24.3 \pm 4.1^{\star}$ \\
\hline D3 $(\mathrm{n}=12)$ & $568 \pm 105^{\star}$ & $23.5 \pm 4.7^{\star}$ \\
\hline D7 $(\mathrm{n}=9)$ & $539 \pm 78^{*}$ & $24.1 \pm 3.9^{\star}$ \\
\hline D14 $(\mathrm{n}=6)$ & $905 \pm 126^{*}$ & $36.2 \pm 5.0^{*}$ \\
\hline D30 $(\mathrm{n}=6)$ & $1108 \pm 67^{*}$ & $41.2 \pm 2.6^{*}$ \\
\hline
\end{tabular}

Table 2. Summarized data of infusion volume and time to reach $30 \mathrm{cmH}_{2} 0 .{ }^{\star} \mathrm{P}<0.05$ denotes comparison between control and each period after SCI. 
SCI are lacking. Although there are many reports of DO after recovery from spinal shock ${ }^{30-35}$, we do not know the incidence of DO in human patients during the spinal shock period. Increased NVCs are a sign of DO, and NVCs can be observed within 1 week in rodents after $\mathrm{SCI}^{40}$. The current study showed that DO develops during spinal shock and is sustained after recovery after spinal shock in the animal model used.

Early treatment to avoid higher intravesical pressure with lower bladder compliance followed by vesicoureteral reflux associated with DO has been suggested to keep patients' renal and bladder function serving as a 'low pressure tank' without waiting for the irreversible complications of $\mathrm{SCI}^{34,35}$. Given the importance of an early intervention for a treatment especially focusing on a myogenic aspect, preventing the phenotypic change of $\mathrm{PDGFR}^{+}$cells and rescuing the function of SK channels in bladder PDGFR $\alpha^{+}$cells might be a promising target to avoid development of DO after SCI.

\section{Methods}

Spinal cord injury $(\mathrm{SCl})$ animal model. All experimental procedures were conducted in accordance with the National Institutes of Health Guide for the Care and Use of Laboratory Animals and the animal use protocol, reviewed and approved by the Institutional Animal Use and Care Committee at the University of Nevada. All methods are reported in accordance with ARRIVE guidelines. C57BL/6 (male mice, 8-12 wks old), Pdgfra ${ }^{\text {tm11(EGFP)Sor } / J ~(P D G F R a / e G F P, ~ J a c k s o n ~ l a b) ~ a n d ~ s m M H C / C r e / e G F P ~(S M C / e G F P) ~ f r o m ~ J a c k s o n ~ L a b ~}$ used for SCI operations and age-matched control. Laminectomies were performed under isoflurane anesthesia (3-4\% with a balance of oxygen for induction followed by $2 \%$ for maintenance), and the spinal cord (T11-T13) were exposed without any damage or compression to the surrounding dura. Dumont \# 5 forceps were positioned in the middle of the exposed spinal cord segment to perform complete spinal cord transection. Complete spinal cord transection was done at T 12 confirmed by retraction of rostal and caudal cut ends of spinal cord under surgical microscope, which had a space approximately at $2 \mathrm{~mm}$. Control animals received sham operations with exposing the vertebrae at same level as SCI without damaging any spinal cord and dura. Enrofloxacin $(5 \mathrm{mg} / \mathrm{kg})$ was applied subcutaneously for three days after SCI followed by twice a week after SCI surgery until ex vivo or molecular evaluation was done. The bladder was manually squeezed to eliminate the residual urine of bladder once daily. Bladders were collected for experiments at D1, D3, D7, D14 and D30 after SCI surgery and in sham control.

Ex vivo preparation. Bladders were removed. A PE50 catheter (Intramedic, Fisher Scientific, Santa Clara, CA) with a cuff was placed in the urethral opening and ligated tightly with silk thread just above the ureterovesical junction and constant monitoring of pressure. Intravesical pressure were recorded with reference to atmospheric pressure $(\mathrm{p}=0)$ at the level of the bladder connected to a quad-bridge amplifier (AD Instruments) interfaced to a computer. Krebs-Ringer bicarbonate $(\mathrm{KRB})$ solution $\left(37^{\circ} \mathrm{C}\right)$ was infused $(25 \mu \mathrm{l} / \mathrm{min})$ and stopped when bladder pressures reach $30-40 \mathrm{~cm} / \mathrm{H}_{2} \mathrm{O}$ to avoid a permanent damage ${ }^{4}$. At least 3 fills will be performed under each experimental condition to ensure reproducibility. The effect of apamin was tested on control and spinal cord injured bladder. Ex vivo data were captured using the threshold search by Clampfit 10 (Molecular Device) with baseline adjustment to examine the frequency and amplitude of transient contractions occurring during the filling phase.

Molecular preparation. Dissection of detrusor smooth muscles and RNA isolation in control and SCI were identical as previously described ${ }^{18}$. For quantitative analysis of transcripts, PDGFR $\alpha^{+}$cells and eGFP/SMCs were purified by fluorescence-activated cell sorting and detrusor muscles for molecular tests. Total RNA was isolated from detrusor muscles, PDGFRa ${ }^{+}$cells and eGFP/SMCs using illustra RNAspin Mini RNA Isolation kit (GE Healthcare, Little Chalfont, UK), and first-strand cDNA was synthesized using SuperScript III (Invitrogen, Carlsbad, CA, USA), according to the manufacturer's instructions. PCR was performed with specific primers using Go-Taq Green Master Mix (Promega Corp., Madison, WI, USA). The following PCR primers designed against murine sequences were used (GenBank accession number is given in parentheses for the reference nucleotide sequence used): Pdgfra (NM_011058) and Kcnn3 (NM_080466). Quantitative PCR (qPCR) was performed with the same primers as PCR using Fast SYBR Green chemistry (Applied Biosystems, Foster City, CA, USA) on the 7900HT Real Time PCR System (Applied Biosystems). Regression analysis of the mean values of three multiplex qPCRs for the $\log _{10}$-diluted cDNA was used to generate standard curves. Unknown amounts of messenger RNA (mRNA) were plotted relative to the standard curve for each set of primers and graphically plotted using Microsoft Excel. This gave transcriptional quantification of each gene relative to the endogenous glyceraldehyde 3-phosphate dehydrogenase (Gapdh) standard after log transformation of the corresponding raw data.

Transcriptomes profiled by mRNA-seq (Novogene Co Ltd) were investigated to identify the genes and pathways potentially involved in the regulation of excitability in PDGFRa ${ }^{+}$cells upon SCI treatment. Total RNA was obtained from detrusor muscles in control and SCI. Using the SAM tool ${ }^{41}$, the genes with false discovery rate (FDR) $<5 \%$ and fold change (FC) $>1.5 \%$ were deemed to be differentially expressed. The FAIME algorithm ${ }^{22}$ was applied to assign gene expression-based geneset scores for the "apoptosis" related genes defined by both the Kyoto Encyclopedia of Genes and Genomes (KEGG) ${ }^{42}$ and Gene Ontology (GO) ${ }^{43}$ databases. The FAIME method generates geneset scores using the rank-weighted gene expression of individual samples, which determines whether an a priori defined set of genes shows statistically significant, concordant expression differences between two biological states (e.g. control vs. SCI), and provides a mechanistic interpretation of the deregulated genes.

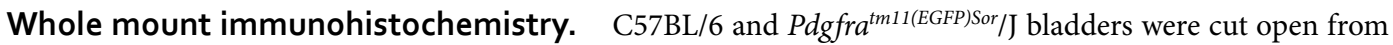
the neck up to the dome. Tissues were dissected in Krebs ringer solution containing $118.5 \mathrm{mM} \mathrm{NaCl}, 4.7 \mathrm{mM}$ 
$\mathrm{KCl}, 2.5 \mathrm{mM} \mathrm{CaCl}_{2}, 1.2 \mathrm{mM} \mathrm{MgCl}$, $23.8 \mathrm{mM} \mathrm{NaHCO}_{3}, 1.2 \mathrm{mM} \mathrm{KH} \mathrm{mO}_{2} \mathrm{PO}$ and $11 \mathrm{mM}$ dextrose, then pinned down on Sylgard dish and stretched $150 \%$ from the resting state. For urothelial denudation, urothelium was removed and surface of the muscle was scraped to remove any residual sub-urothelial cells. Fixation and incubation of tissues were identical as previously described ${ }^{16}$. For double labelling studies, tissues were re-blocked for $1 \mathrm{~h}$ in $10 \%$ normal donkey serum (Sigma-Aldrich) and incubated overnight in antibody of choice, diluted in $0.5 \%$ Triton-X (Sigma-Aldrich) and incubated in the appropriate Alexa Fluor (Invitrogen) antibody diluted 1:1000 in PBS for $1 \mathrm{~h}$. Processed tissues were mounted with Aqua mount mounting media (Lerner Laboratories, Pittsburgh, PA, USA) on glass slides and cover slipped and imaged. The primary antibodies of PDGFR (R\&D Systems, Inc.) and SK3 (Alamone Labs) were used and primary antibodies were omitted in the procedure for negative controls.

Automated capillary electrophoresis and chemiluminescent western blotting. Muscles were snap-frozen in liquid $\mathrm{N}_{2}$, and stored at $-80^{\circ} \mathrm{C}$. For analysis, the methods for homogenization, centrifugation and collection of the supernatants were identical as previously reported ${ }^{44,45}$. Protein concentrations were determined by Bradford assay ${ }^{45}$. Analysis of protein expression was performed according to the User Guide using a ProteinSimple Wes instrument (CA, USA). Each sample was mixed with fluorescent $5 \times$ Master Mix, incubated at $95^{\circ} \mathrm{C}$ for $5 \mathrm{~min}$ and then loaded into a Wes $12-230 \mathrm{kDa}$ prefilled plate, along with a biotinylated protein ladder, blocking buffer, primary antibodies, ProteinSimple HRP-conjugated anti-rabbit secondary antibody, luminol peroxide, and washing buffer. The plates and capillary cartridges were placed into the Wes for electrophoresis and chemiluminescence immunodetection by a CCD camera using default settings. Compass software was used to acquire and analyze the data and generate gel images and chemiluminescence intensities. Protein expression levels are expressed as the chemiluminescence intensity area under the primary antibody peak per $\mu \mathrm{g}$ protein.

Drugs. All reagents were purchased from Sigma-Aldrich (St Louis, MO, USA) and apamin (Tocris, UK) solubilized in the bath solution for ex vivo recordings.

Statistical analyses. All data are expressed as means \pm SEM. "n" represents the number of experiments. All statistical analyses were performed using Graphpad Prism. A paired and unpaired Student's $t$ test was used to compare groups of data and differences were considered to be significant at $P<0.05$.

Received: 7 May 2021; Accepted: 23 July 2021

Published online: 11 August 2021

\section{References}

1. Wein, A. J. Normal and abnormal function: An overview, bladder dysfunction in the adult: The basis for Clinical Management. Curr. Clin. Urol. (Springer, New York) 14, 19-22 (2014).

2. Wellner, M. C. \& Isenberg, G. Properties of stretch-activated channels in myocytes from the guinea-pig urinary bladder. J. Physiol. 466, 213-227 (1993).

3. Wellner, M. C. \& Isenberg, G. Stretch effects on whole-cell currents of guinea-pig urinary bladder myocytes. J. Physiol. 480(Pt 3), 439-448 (1994).

4. Heppner, T. J., Tykocki, N. R., Hill-Eubanks, D. \& Nelson, M. T. Transient contractions of urinary bladder smooth muscle are drivers of afferent nerve activity during filling. J. Gen. Physiol. 147, 323-335. https://doi.org/10.1085/jgp.201511550 (2016).

5. Drake, M. J. et al. Partial outlet obstruction enhances modular autonomous activity in the isolated rat bladder. J. Urol. 170, $276-279$. https://doi.org/10.1097/01.ju.0000069722.35137.e0 (2003).

6. Gillespie, J. I. Phosphodiesterase-linked inhibition of nonmicturition activity in the isolated bladder. BJU Int. 93, 1325-1332. https://doi.org/10.1111/j.1464-410X.2004.04840.x (2004).

7. Parsons, B. A., Drake, M. J., Gammie, A., Fry, C. H. \& Vahabi, B. The validation of a functional, isolated pig bladder model for physiological experimentation. Front. Pharmacol. 3, 52. https://doi.org/10.3389/fphar.2012.00052 (2012).

8. Vahabi, B. \& Drake, M. J. Physiological and pathophysiological implications of micromotion activity in urinary bladder function. Acta Physiol. (Oxf) 213, 360-370. https://doi.org/10.1111/apha.12373 (2015).

9. Iijima, K., Igawa, Y., Wyndaele, J. J. \& De Wachter, S. Mechanosensitive primary bladder afferent activity in rats with and without spinal cord transection. J. Urol. 182, 2504-2510. https://doi.org/10.1016/j.juro.2009.07.012 (2009).

10. Kanai, A. \& Andersson, K. E. Bladder afferent signaling: Recent findings. J. Urol. 183, 1288-1295. https://doi.org/10.1016/j.juro. 2009.12.060 (2010).

11. Satchell, P. \& Vaughan, C. Efferent pelvic nerve activity, ganglionic filtering, and the feline bladder. Am. J. Physiol. 256, R1269-1273 (1989).

12. Yu, Y. \& de Groat, W. C. Sensitization of pelvic afferent nerves in the in vitro rat urinary bladder-pelvic nerve preparation by purinergic agonists and cyclophosphamide pretreatment. Am. J. Physiol. Renal Physiol. 294, F1146-1156. https://doi.org/10.1152/ ajprenal.00592.2007 (2008).

13. McCloskey, K. D. et al. Comparison of mechanical and electrical activity and interstitial cells of Cajal in urinary bladders from wild-type and W/Wv mice. Br. J. Pharmacol. 156, 273-283. https://doi.org/10.1111/j.1476-5381.2008.00006.x (2009).

14. McCloskey, K. D. \& Gurney, A. M. Kit positive cells in the guinea pig bladder. J. Urol. 168, 832-836 (2002).

15. Gevaert, T. et al. The stem cell growth factor receptor KIT is not expressed on interstitial cells in bladder. J. Cell Mol. Med. 21, 1206-1216. https://doi.org/10.1111/jcmm.13054 (2017).

16. Koh, B. H. et al. Platelet-derived growth factor receptor-alpha cells in mouse urinary bladder: A new class of interstitial cells. J. Cell Mol. Med. 16, 691-700. https://doi.org/10.1111/j.1582-4934.2011.01506.x (2012).

17. Lee, H. et al. Premature contractions of the bladder are suppressed by interactions between TRPV4 and SK 3 channels in murine detrusor PDGFRalpha+ cells. Sci. Rep. 7, 12245. https://doi.org/10.1038/s41598-017-12561-7 (2017).

18. Lee, H., Koh, B. H., Peri, L. E., Sanders, K. M. \& Koh, S. D. Functional expression of SK channels in murine detrusor PDGFR+ cells. J. Physiol. 591, 503-513. https://doi.org/10.1113/jphysiol.2012.241505 (2013).

19. Lee, H., Koh, B. H., Peri, L. E., Sanders, K. M. \& Koh, S. D. Purinergic inhibitory regulation of murine detrusor muscles mediated by PDGFRalpha+ interstitial cells. J. Physiol. 592, 1283-1293. https://doi.org/10.1113/jphysiol.2013.267989 (2014).

20. Lee, H. et al. UTP activates small-conductance Ca2+-activated K+ channels in murine detrusor PDGFRalpha+ cells. Am. J. Physiol. Renal Physiol. 309, F569-574. https://doi.org/10.1152/ajprenal.00156.2015 (2015). 
21. Brading, A. F. \& Turner, W. H. The unstable bladder: Towards a common mechanism. Br. J. Urol. 73, 3-8 (1994).

22. Yang, X. et al. Single sample expression-anchored mechanisms predict survival in head and neck cancer. PLoS Comput. Biol. 8, e1002350. https://doi.org/10.1371/journal.pcbi.1002350 (2012).

23. Koh, S. D., Lee, H., Ward, S. M. \& Sanders, K. M. The mystery of the interstitial cells in the urinary bladder. Annu. Rev. Pharmacol. Toxicol. https://doi.org/10.1146/annurev-pharmtox-010617-052615 (2017).

24. Thorneloe, K. S. et al. Small-conductance, $\mathrm{Ca}(2+)$-activated $\mathrm{K}+$ channel 2 is the key functional component of SK channels in mouse urinary bladder. Am. J. Physiol. Regul. Integr. Comp. Physiol. 294, R1737-1743. https://doi.org/10.1152/ajpregu.00840.2006 (2008).

25. Parajuli, S. P., Soder, R. P., Hristov, K. L. \& Petkov, G. V. Pharmacological activation of small conductance calcium-activated potassium channels with naphtho[1,2-d] thiazol-2-ylamine decreases guinea pig detrusor smooth muscle excitability and contractility. J. Pharmacol. Exp. Ther. 340, 114-123. https://doi.org/10.1124/jpet.111.186213 (2012).

26. Afeli, S. A., Rovner, E. S. \& Petkov, G. V. SK but not IK channels regulate human detrusor smooth muscle spontaneous and nerveevoked contractions. Am. J. Physiol. Renal Physiol. 303, F559-568. https://doi.org/10.1152/ajprenal.00615.2011 (2012).

27. Herrera, G. M. et al. Urinary bladder instability induced by selective suppression of the murine small conductance calcium-activated potassium (SK3) channel. J. Physiol. 551, 893-903. https://doi.org/10.1113/jphysiol.2003.045914 (2003).

28. de Groat, W. C. A neurologic basis for the overactive bladder. Urology 50, 36-52 (1997) ((discussion 53-36)).

29. Choudhary, M., van Asselt, E., van Mastrigt, R. \& Clavica, F. Neurophysiological modeling of bladder afferent activity in the rat overactive bladder model. J. Physiol. Sci. 65, 329-338. https://doi.org/10.1007/s12576-015-0370-y (2015).

30. Coelho, A., Oliveira, R., Cruz, F. \& Cruz, C. D. Impairment of sensory afferents by intrathecal administration of botulinum toxin A improves neurogenic detrusor overactivity in chronic spinal cord injured rats. Exp. Neurol. 285, 159-166. https://doi.org/10. 1016/j.expneurol.2016.05.029 (2016).

31. Dorsher, P. T. \& McIntosh, P. M. Neurogenic bladder. Adv. Urol. 2012, 816274. https://doi.org/10.1155/2012/816274 (2012).

32. Miyazato, M., Yoshimura, N. \& Chancellor, M. B. The other bladder syndrome: Underactive bladder. Rev. Urol. 15, 11-22 (2013).

33. Taweel, W. A. \& Seyam, R. Neurogenic bladder in spinal cord injury patients. Res. Rep. Urol. 7, 85-99. https://doi.org/10.2147/ RRU.S29644 (2015).

34. Bywater, M., Tornic, J., Mehnert, U. \& Kessler, T. M. Detrusor acontractility after acute spinal cord injury-myth or reality?. J. Urol. 199, 1565-1570. https://doi.org/10.1016/j.juro.2018.01.046 (2018).

35. Watanabe, T. et al. High incidence of occult neurogenic bladder dysfunction in neurologically intact patients with thoracolumbar spinal injuries. J. Urol. 159, 965-968 (1998).

36. McGuire, E. J. \& Savastano, J. A. Urodynamics and management of the neuropathic bladder in spinal cord injury patients. J. Am. Paraplegia Soc. 8, 28-32 (1985).

37. Pikov, V., Gillis, R. A., Jasmin, L. \& Wrathall, J. R. Assessment of lower urinary tract functional deficit in rats with contusive spinal cord injury. J. Neurotrauma 15, 375-386. https://doi.org/10.1089/neu.1998.15.375 (1998).

38. Ryu, J. C. et al. Role of proNGF/p75 signaling in bladder dysfunction after spinal cord injury. J. Clin. Invest. 128, 1772-1786. https:// doi.org/10.1172/JCI97837 (2018).

39. Watanabe, T., Rivas, D. A. \& Chancellor, M. B. Urodynamics of spinal cord injury. Urol. Clin. N. Am. 23, 459-473 (1996).

40. McCarthy, C. J. et al. Spontaneous contractions evoke afferent nerve firing in mouse bladders with detrusor overactivity. J. Urol. 181, 1459-1466. https://doi.org/10.1016/j.juro.2008.10.139 (2009).

41. Tusher, V. G., Tibshirani, R. \& Chu, G. Significance analysis of microarrays applied to the ionizing radiation response. Proc. Natl. Acad .Sci. U S A 98, 5116-5121. https://doi.org/10.1073/pnas.091062498 (2001).

42. Kanehisa, M. \& Goto, S. KEGG: Kyoto encyclopedia of genes and genomes. Nucleic Acids Res. 28, 27-30. https://doi.org/10.1093/ nar/28.1.27 (2000).

43. Ashburner, M. et al. Gene ontology: Tool for the unification of biology. The Gene Ontology Consortium. Nat. Genet. 25, 25-29. https://doi.org/10.1038/75556 (2000).

44. Dudem, S. et al. LINGO1 is a regulatory subunit of large conductance, Ca(2+)-activated potassium channels. Proc. Natl. Acad. Sci. US A 117, 2194-2200. https://doi.org/10.1073/pnas.1916715117 (2020).

45. Li, W., Sasse, K. C., Bayguinov, Y., Ward, S. M. \& Perrino, B. A. Contractile protein expression and phosphorylation and contractility of gastric smooth muscles from obese patients and patients with obesity and diabetes. J. Diabetes Res. 2018, 8743874. https://doi. org/10.1155/2018/8743874 (2018).

\section{Author contributions}

K.L., S.O.P., P.C.C., S.-B.R., S.B.M. and H.L. performed spinal cord surgery. Ex vivo data were collected and analyzed by K.L., S.O.P., P.C.C., S.-B.R., R.D.C., A.C.Y., S.B.M. and H.L. H.L. and L.E.P. performed cell sorting and molecular study. T.Z. analyzed RNA-seq data. Immunohistochemistry were performed by A.C.Y. and S.B.M. and W.E.S. were performed by B.A.P. K.M.S. and S.D.K. shared in the design of experiments, interpretation of the data and the writing of the manuscript. All authors approved the final version of the manuscript.

\section{Funding}

This research was supported by the NIH/NIDDK R01 DK098388 for SDK and Seoul National University Hospital (No. 0520190030) for S-B R.

\section{Competing interests}

The authors declare no competing interests.

\section{Additional information}

Correspondence and requests for materials should be addressed to S.D.K.

Reprints and permissions information is available at www.nature.com/reprints.

Publisher's note Springer Nature remains neutral with regard to jurisdictional claims in published maps and institutional affiliations. 
(c) (i) Open Access This article is licensed under a Creative Commons Attribution 4.0 International cc) License, which permits use, sharing, adaptation, distribution and reproduction in any medium or format, as long as you give appropriate credit to the original author(s) and the source, provide a link to the Creative Commons licence, and indicate if changes were made. The images or other third party material in this article are included in the article's Creative Commons licence, unless indicated otherwise in a credit line to the material. If material is not included in the article's Creative Commons licence and your intended use is not permitted by statutory regulation or exceeds the permitted use, you will need to obtain permission directly from the copyright holder. To view a copy of this licence, visit http://creativecommons.org/licenses/by/4.0/.

(C) The Author(s) 2021 